\title{
An Unusual Subacute Progressive Motor Neuronopathy with Myasthenia-like Features
}

\author{
J.H. Noseworthy, A.D. Rae-Grant, W.F. Brown
}

\begin{abstract}
The initial presentation and clinical course of this 60-year old woman suggested a diagnosis of myasthenia gravis. The subsequent development of tongue fasciculations and the lack of response to treatment made a diagnosis of amyotrophic lateral sclerosis (ALS) more likely despite the presence of conjugate gaze paresis and the absence of many of the typical clinical and electromyographic (EMG) findings seen in this condition. The pathological findings were consistent with either a motor neuronopathy or an unusual variant of ALS. We review the clinical and pathological features of this unusual case in this report.
\end{abstract}

RÉSUMÉ: Neuropathie motrice progressive subaiguë inusitée La présentation initiale et l'évolution clinique de la maladie chez cette femme âgée de 60 ans suggéraient un diagnostic de myasthénie grave. Par la suite, l'apparition de fasciculations à la langue et l'absence de réponse au traitement a orienté le diagnostic vers une sclérose latérale amyotrophique (SLA), malgré la présence d'une parésie des mouvements oculaires conjugués et l'absence de plusieurs des caractéristiques cliniques et électromyographiques typiques de cette affection. Les constatations anatomopathologiques étaient compatibles soit avec une neuronopathie motrice ou une variante inhabituelle de la SLA. Nous revoyons les caractéristiques cliniques et pathologiques de ce cas inusité.

Can. J. Neurol. Sci. 1988; 15:304-309

It may be difficult to distinguish early amyotrophic lateral sclerosis (ALS) from myasthenia gravis. This diagnostic difficulty is usually clarified by the evolution of the clinical findings, ancillary diagnostic studies, and the response to therapeutic measures. We describe a patient whose presentation suggested myasthenia gravis, but who turned out to have either a motor neuronopathy or an unusual form of ALS. Despite gaze paresis and the absence of characteristic electromyographic (EMG) changes, ALS was suspected when fasciculations developed in the tongue and subsequently in clinically weak limb muscles. Post mortem studies revealed evidence of a motor neuronopathy accompanied by involvement of the abducens nuclei.

\section{CASE REPOR'T}

A 60-year old woman noted a six week history of progressive ptosis, blurred vision without diplopia, dysarthria, dysphagia for liquids, mild proximal weakness of the upper extremities, and an $11 \mathrm{~kg}$ weight loss. These symptoms were less troublesome early in the day.

Physical examination revealed bilateral basilar rales, a pleural friction rub, severe dysarthria with marked imprecision of consonant articulation, pronounced hypernasality, and difficulty clearing oral secretions. Non-fatiguable ptosis and a right gaze palsy uncorrected by oculocephalic testing were present. There was mild bilateral weakness of trigeminal and facial muscles, moderate weakness of shoulder abduction, elbow flexion and extension, hip flexion and dorsiflexion of the left foot. Neck flexion was severely weak. No wasting or fasciculations of muscles were seen initially. Otherwise, the neurological examination was normal.

Myasthenia gravis was suspected clinically but the response to 10 $\mathrm{mg}$ of edrophonium was equivocal. An abnormal decrement in the maximum thenar " $M$ " potential in response to repetitive supramaximal stimulation of the median nerve at $3 \mathrm{~Hz}$ was accompanied by posttetanic exhaustion and post-tetanic facilitation induced by exercise (Figure 1). Prednisone was started ( $40 \mathrm{mg}$ daily). Her admission chest $\mathrm{X}$-ray showed evidence of aspiration. A CT scan of the chest showed no evidence of thymoma. The following laboratory tests were normal: complete blood count, erythrocyte sedimentation rate, routine biochemistry, thyroid function studies, creatine kinase, protein electrophoresis, immunoglobulins, complement, rheumatoid factor, antinuclear antibody, VDRL, porphyrin studies, botulinum toxin assay, pelvic ultrasound, CT scan and MRI of the head. Cerebrospinal fluid (CSF) analysis was normal except that on one occasion the CSF protein was elevated at $1,122 \mathrm{mg} / \mathrm{L}(150-450 \mathrm{mg} / \mathrm{L})$. The acetylcholine receptor $(\mathrm{AChR})$ antibody assay was equivocal at one unit.

She did not improve despite increasing doses of prednisone. On the 24th hospital day tongue fasciculations were seen prior to initiating anticholinesterase medications. Needle electromyographic studies, however, failed to show fibrillation potentials or positive sharp waves or any abnormalities in the shape and size of motor unit action potentials in muscles judged clinically to be weak. On the 28th day aspiration pneumonia developed with subsequent respiratory failure requiring

From the Department of Clinical Neurological Sciences. University of Western Ontario, London

Received June 16, 1987. Accepted in final form March 6, 1988

Presented in part at the XXIInd Canadian Congress of Neurological Sciences, Vancouver, British Columbia, June, 1987

Reprint requests to: John H. Noseworthy, M.D., Department of Clinical Neurological Sciences, University Hospital, 339 Windermere Road, P.O. Box 5339, London, Ontario, Canada N6A 5A5 


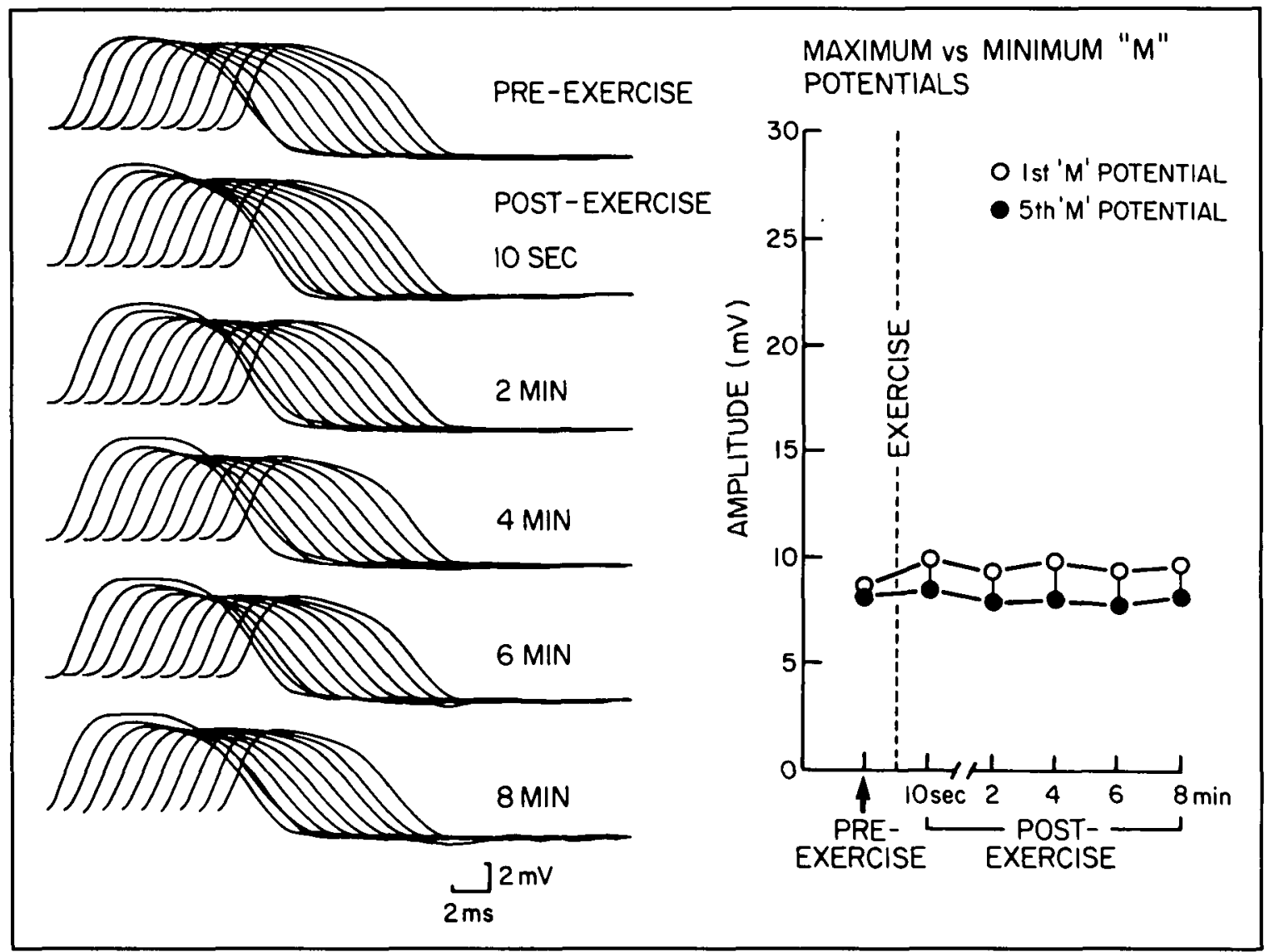

Figure I - Electrophysiological studies (day 2) demonstrating an abnormal decremental response to repetitive stimulation at 3 $\mathrm{Hz}$ in the trapezius muscles with post-letanic exthaustion and post-tetanic facilitation induced by exercise. The percentage difference of largest to smallest " $M$ " potential is not significant pre-exercise (6\%) but is clearly abnormal following exercise $(18 \%)$.

intubation. Following edrophonium, her vital capacity transiently improved from $550 \mathrm{ml}$ to $775 \mathrm{ml}$ increasing further $101300 \mathrm{ml}$ after plasma exchange on 3 successive days. This temporary improvement allowed her to be extubated for 24 hrs. Shortly after this brief respite, her respiratory status once again deteriorated so that she became ventilator-dependent from hospital days 34 through 84 . Through this latter period there was no further improvement despite prednisone $50 \mathrm{mg}$ daily, pyridostigmine, and fourteen additional plasma exchanges. Fatigable ptosis or exercise-induced limb weakness were never present but she developed mild distal weakness in all extremities, and moderate wasting without fasciculations in the legs. Muscle tone, tendon reflexes, and plantar responses remained normal. EMG studies were repeated on day 54 but again failed to show any abnormal insertional or spontaneous activity. As the maximum compound muscle action potentials were within the normal range in respect to size in clinically weak muscles, and as no increment in the size of these potentials occurred in response to stimulation at $30 \mathrm{~Hz}$, it was felt she did not have the EatonLambert myasthenic syndrome. A left conjugate gaze paresis was noted in addition to the right gaze palsy (day 76). Bulbar and appendicular strength progressively worsened. On the 76 th day EMG studies revealed for the first time substantial reductions in the size of the maximum compound muscle action potentials in the facial muscles unaccompanied by any increment following either exercise or high frequency repetitive stimulation. In the trapezius muscle an abnormal decrement (greater than 20\%) accompanied by post-tetanic facilitation and exhaustion were seen but as before needle electromyographic studies still failed to show any fibrillation activity or fasciculations in selected proximal, intermediate and distal muscles. Azathioprine was added on day 77 and on the 84th day she was successfully weaned from the ventilator. Repeat AChR antibody assay was negative. Muscle biopsy showed grouping of small angulated fibers consistent with small motor unit atrophy (denervation atrophy). On the 103rd hospital day, fasciculations were seen for the first time in clinically weak extremity muscles and needle electromyographic studies on days 110 and 119 revealed moderate to abundant fibrillation activity and fasciculations in the forearm and intrinsic hand muscles, and occasional fibrillation potentials and positive sharp waves in the extensor digitorum brevis and plantar foot muscles. In these latter muscles recruitment was incomplete and motor unit action potentials were abnomally large in amplitude. There was no evidence of a presynaptic or postsynaptic neuromuscular transmission disorder or of an inflammatory muscle disease. She died on the 125th hospital day.

\section{AUTOPSY FINDINGS}

The general autopsy revealed pulmonary edema, atelectasis of the lower lobes, and evidence of aspiration. The thymus was normal. The brain (1420 grams) was grossly normal. There was minimal cerebral atherosclerosis. The precentral gyrus was not atrophic. The ventral nerve roots were greyer than normal.

\section{Microscopic Description (Table 1)}

Cerebrum: Multiple sections of the cerebral cortex including the premotor cortex were of normal appearance. No gliosis, hyaline inclusions, bunina bodies, or other degenerative neuronal changes were present. The apparent number of motor neurons was normal in all sections studied. Scant neurofibrillary tangles and senile plaques were present in the hippocampi. The 
Table 1: Summary of Pathological Changes

\begin{tabular}{lccc}
\hline \hline ANATOMIC & $\begin{array}{c}\text { NEURON } \\
\text { SITE }\end{array}$ & $\begin{array}{c}\text { NEURON } \\
\text { LOSS }\end{array}$ & GLIOSIS \\
\hline Cortex, premotor & 0 & 0 & 0 \\
Cortex, other & 0 & 0 & 0 \\
Basal ganglia & 0 & 0 & 0 \\
White matter & 0 & 0 & 0 \\
Third Nerve Nucleus & + & 0 & + \\
Fourth Nerve Nucleus & + & 0 & + \\
Fifth Motor Nucleus & +++ & ++ & +++ \\
Sixth Nerve Nucleus & ++++ & +++ & ++++ \\
Seventh Nerve Nucleus & +++ & +++ & +++ \\
Dorsal Motor Nucleus $(X)$ & + & + & + \\
Nucleus Ambiguus & ++ & $?$ & ++ \\
Accessory Nucleus & ++++ & +++ & +++ \\
Hypoglossal Nucleus & +++ & ++++ & ++++ \\
Anterior Horn Cells & +++ & +++ & ++ \\
Clarke's Nucleus & 0 & 0 & 0 \\
Corticospinal tract & 0 & 0 & 0 \\
Sacral Segments & 0 & 0 & 0 \\
\hline
\end{tabular}

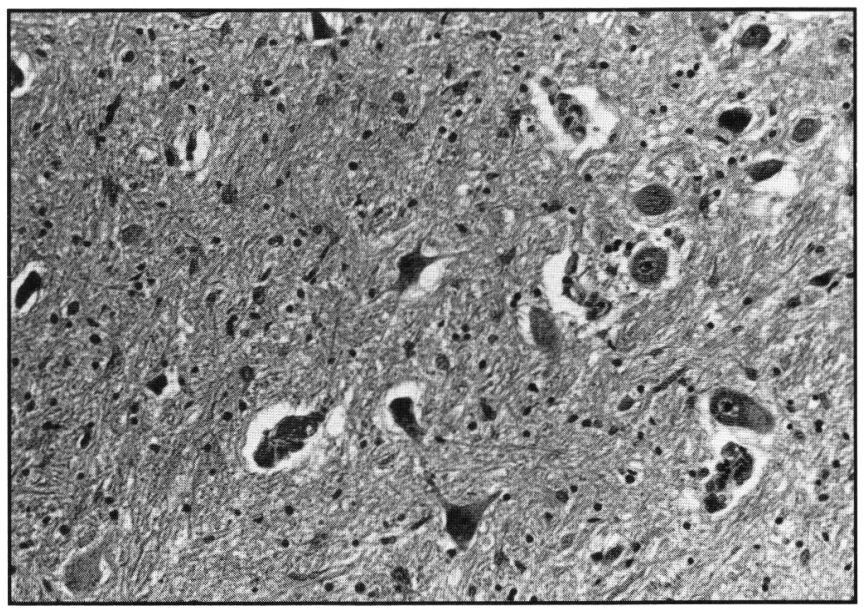

Figure $2-$ Left sixth nerve nucleus showing variable degeneration of motor neurons with lipofuscin deposits, simple atrophy, and moderate gliosis. (H+E, $16 \times 10$ magnification)

internal capsule was normally myelinated, and the caudate, putamen, globus pallidus, and thalamus were normal.

Brainstem: The cerebral peduncles were fully myelinated. The oculomotor nuclei showed mild gliosis, lipofuscin deposition in motor neurons, and some pyknotic, dark neurons with dendritic corkscrew processes consistent with simple neuronal atrophy. A scant perivascular infiltrate surrounded a few small vessels adjacent to the oculomotor nuclei. Similar changes were present in the trochlear nuclei, but in neither of these nuclei were these changes marked, nor was the cellularity visibly diminished. The substantia nigra was normal.

The abducens nuclei were intensely gliotic, with gemistocytic and occasionally binucleate astrocytes (Figure 2). There were some degenerating neurons present in varying stages of destruction: some were normal with undisrupted Nissl substance and dendritic processes; others showed intracytoplasmic accumulations of lipofuscin granules, simple atrophy, and hyaline body inclusions. There were swollen, pale, chromatolytic-like cells within the abducens nuclei consistent with ghost neurons. The

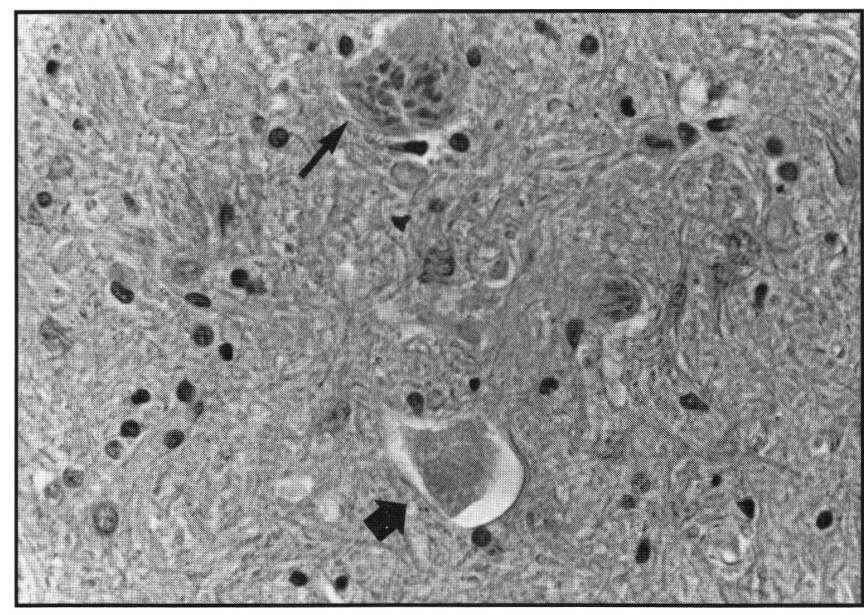

Figure 3 - Left seventh nerve nucleus showing a relatively preserved neuron (arrow), and a "ghost" neuron (arrowhead) with gliosis. $(H+E .400 x)$

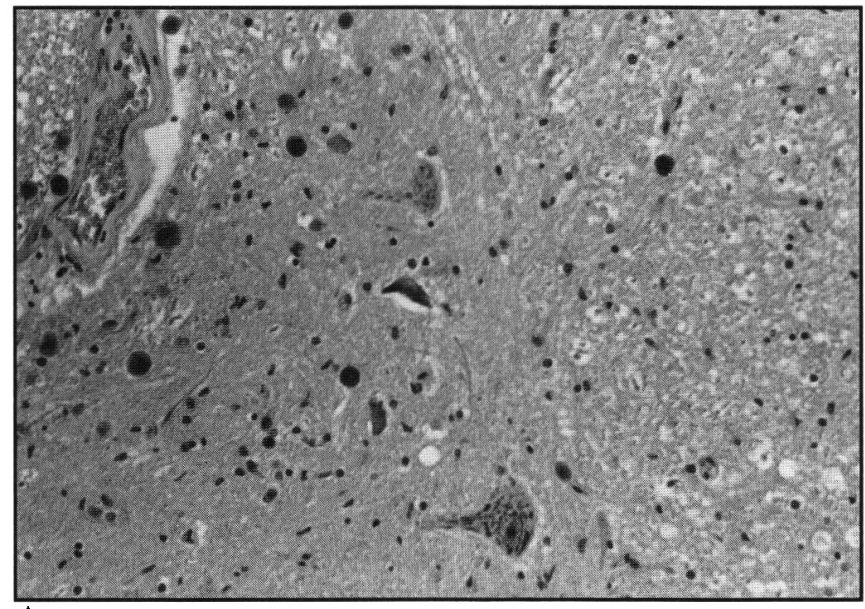

A

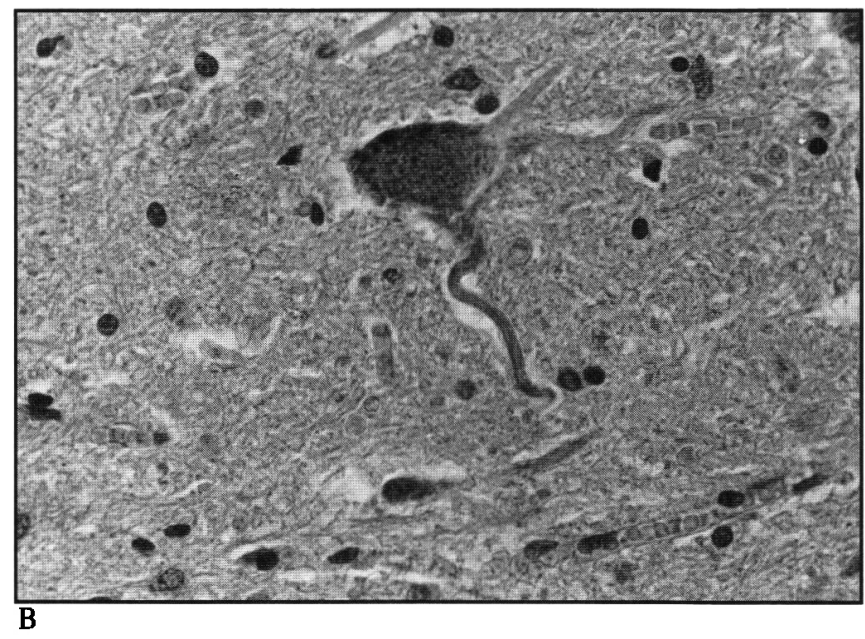

Figure 4-High cervical spinal cord. A. Low power view of the anterior horn showing cells in various stages of degeneration $(H+E, I 60 x) . B$ High power view of the anterior horn showing gliosis and a netwron with simple atrophy and a corkscrew process $(H+E, 400 x)$. 
overall number of motor neurons was visibly diminished. Similar changes were present in the motor nucleus of the trigeminal nerve and in the nucleus of the facial nerve (Figure 3 ). The pontine nuclei, basis pontis white matter, and nucleus of the spinal tract of the trigeminal nerve were normal. Gliosis spread out from the affected nuclei into surrounding white matter but tapered rapidly to nil.

In the hypoglossal nuclei there was marked gliosis with many reactive astrocytes, there was a severe loss of neurons, and the remaining neurons showed variable neuronal degeneration. There were scant perivascular inflammatory infiltrates. There was mild gliosis in the trigeminal spinal nucleus and tract and in the dorsal motor nucleus of the vagus. The nuclei and white matter of the medulla were otherwise normal.

Spinal Cord: Diffuse changes were present in the spinal cord, particularly in the upper cervical segments (Figure 4). In the highest cervical segments marked gliosis and neuronal degeneration were present in the nuclei of the accessory nerve similar to changes previously described. There was a marked loss of motor neurons and moderate gliosis in the anterior horns. Questionable bunina bodies were seen in a few neurons. The motor neurons showed a spectrum of changes from normal to ghost cells with some hyaline inclusions and atrophic cells. The medial ventral horns in the highest cervical segments showed the most florid motor neuron changes and gliosis. The white matter was normal in myelin and axonal stains. The intermediolateral cell column, the nucleus dorsalis of Clarke, and the sacral segments were intact.

Peripheral nerves: Plastic imbedded, toluidine blue stained sections of phrenic nerve, common, deep and superficial peroneal nerves, and intercostal nerve were normal.

Muscles: Sections of the tongue showed neurogenic atrophy with a diffuse loss of muscle fibers, grouped fiber atrophy, and infiltration of fibrous and fatty tissue. Sections from the diaphragm showed angular fibers as well as grouped fiber atrophy. Sections of the tibialis anterior showed severe denervation atrophy. The biceps and medial rectus muscles were normal.

\section{DisCUSSION}

This patient's clinical presentation, the findings of posttetanic exhaustion and exercise induced post-tetanic facilitation at the time of the initial EMG studies, and the apparent initial improvement of the vital capacity with edrophonium and plasma exchange suggested a diagnosis of myasthenia gravis. Subsequent studies failed to confirm a defect in neuromuscular transmission. The initially equivocal and subsequently negative AChR antibody assays failed to support this diagnosis.

This patient was felt to be similar to a group of AChR antibody negative myasthenia gravis patients recently described ${ }^{1}$ in that she had predominant involvement of bulbar, respiratory, and ocular muscles without obvious thymic involvement. After considering the gratifying response to plasma exchange in this published series, ${ }^{1}$ and as there were a number of features atypical for ALS (gaze paresis, the absence of corticospinal tract and lower motor neuron involvement, the absence of EMG changes typical of ALS), she was treated with measures known to induce remission in myasthenia gravis. The subsequent lack of response to prednisone, azathioprine, pyridostigmine, and plasma exchange and the development of atrophy with fasciculations in the extremities together with the changes of neurogenic atrophy on muscle biopsy suggested that ALS was the correct diagnosis.

The autopsy findings do not entirely clarify the situation. The findings of motor neuron changes in the fifth (motor) nucleus, seventh nerve nucleus, accessory and hypoglossal nuclei, and anterior horn cells were consistent with ALS. The finding of neuronal degeneration in varying stages from normal to complete loss of nuclear detail was also consistent with this diagnosis. ${ }^{2}$ In addition to the previously mentioned unusual clinical and laboratory features, however, some of the neuropathological findings were atypical for ALS. Definite abnormalities were seen in the abducens nuclei and nearby white matter. Similar changes have been described in ALS but are uncommon. There were no signs of upper motor neuron pathology. This has been reported previously in ALS, ${ }^{3}$ and in this case corresponds well with the absence of clinical evidence of upper motor neuron dysfunction. Similarly, proximal axonal swellings were not seen in brainstem motor nuclei or in the anterior horns, ${ }^{4}$ but these changes are not invariably seen in ALS. ${ }^{2}$ The perivascular inflammatory infiltrates noted in the brainstem are unexplained. There were no other pathological changes to suggest a viral etiology, but viral studies were not performed during life. Because of these uncertainties, this woman's illness may have been due to an unusual subacute progressive motor neuronopathy, ${ }^{5}$ but it is not clear in this case that this represents a different nosological entity from ALS.

Her clinical presentation and course merit further comment. Patients with ALS may have symptoms and findings suggesting myasthenia gravis at onset. Fatigable muscle weakness which responds to brief periods of rest is not uncommon. 6 They may have electrophysiological findings of a decremental response to repetitive stimulation which may be maximized by exercise and respond to edrophonium suggesting an impairment of neuromuscular transmission. ${ }^{7-11}$

Table 2: Eye Movement Disorders in Motor Neuron Disease

\begin{tabular}{|c|c|c|}
\hline Authors & Clinical Findings & Neuropathology \\
\hline $\begin{array}{l}\text { Lawyer and } \\
\text { Netsky (1953) }\end{array}$ & No eye movement abnormalities repored & $\begin{array}{l}4 / 53 \text { auropsy cases chanjes } \\
\text { seen in cells of nucleus of IIJ }\end{array}$ \\
\hline $\begin{array}{l}\text { Walsh and } \\
\text { Hoyt (1969) }\end{array}$ & I case progressive complete external ophthalmoplegia & . \\
\hline $\begin{array}{l}\text { Esteban el al } \\
(1978)\end{array}$ & $\begin{array}{l}24 \text { ALS patients - aculocephalic reflex normal } \\
\text { 15/24 Bell's phenomenon abnormal (abolished or } \\
\text { inverted) } \\
3 / 15 \text { upgaze palsy } \\
2 \text { of these - voluntary horizontal eye movements absent } \\
\text { - spasmotic fixation of gaze } \\
\text { - loss of voluntary eye closure }\end{array}$ & $\begin{array}{l}\text { Speculated these supranuele sr } \\
\text { disorders due to bituteral cor. } \\
\text { ticogeniculate tract lesions }\end{array}$ \\
\hline $\begin{array}{l}\text { Harvey ct al } \\
\text { (I979) }\end{array}$ & I case ALS complece exiernal ophthulnoplegia & $\begin{array}{l}\text { Neuronal loss and gliosis in } \\
\text { nuclei III. IV. VI }\end{array}$ \\
\hline $\begin{array}{l}\text { Jacobs et al } \\
\text { (1981) }\end{array}$ & $\begin{array}{l}\text { 9/18 ALS cases clinically obvious pursuit disorder } \\
\text { 3/18 defective saccades }\end{array}$ & $\begin{array}{l}\text { I case degencration of sub- } \\
\text { stantia nigra neumns with } \\
\text { imtermal capsule demyelination }\end{array}$ \\
\hline $\begin{array}{l}\text { Leveille et a! } \\
\text { (1982) }\end{array}$ & $\begin{array}{l}\text { 4/10 rapidly progressing, advanced ALS patients had decreased } \\
\text { saccadic or smooth pursuit velocities by electro-oculography } \\
\text { 1/4 unidirectional saccadic pursuit } \\
\text { Postulated a supranuclear lesion }\end{array}$ & $\cdots$ \\
\hline $\begin{array}{l}\text { McGlone and } \\
\text { Hudson (1983) }\end{array}$ & $\begin{array}{l}9 \text { consecutive ALS patients impaired visual scanning (Geneva } \\
\text { Lines Test) } \\
\text { Speed of eye movements slower in ALS } \\
\text { Intact visual search function }\end{array}$ & $\ldots$ \\
\hline $\begin{array}{l}\text { Kushner et al } \\
\text { (1984) }\end{array}$ & $\begin{array}{l}2 \text { ALS patienis with gaze-cvoked rotatory nystagnus } \\
1 \text { also had - } 1^{\circ} \text { position horizontal nystagmus } \\
- \text { supranuclear paresis horizontal and vertical gaze }\end{array}$ & $\begin{array}{l}1 \text { cuse occasional neuronal } \\
\text { central chromatolysis nuclei } \\
\text { III and VI }\end{array}$ \\
\hline
\end{tabular}


Clinically obvious disturbances of ocular motility occur infrequently in ALS (Table 2).4,12-22 As such, the presence of ocular symptoms, together with sensory complaints, dementia, and bladder difficulty generally suggest an alternate diagnosis. ${ }^{12}$ Others have drawn attention to neuronal loss and gliosis in the cranial nerve nuclei responsible for extraocular movements in patients with little or no clinical evidence of a disturbance of oculomotor function. 13-15 Our patient complained of blurred vision and difficulty maintaining eyelid opening and demonstrated a variable degree of ptosis and horizontal gaze paresis which was neither clearly fatigable nor responsive to edrophonium. Bedside examination suggested this disturbance was not supranuclear in that the right gaze paresis could not be overcome by oculocephalic testing. Unfortunately, further tests of vestibular stimulation were not performed to distinguish whether the right gaze paresis was caused by a lesion of the paramedian pontine reticular formation (PPRF) in the upper pons (reversal of gaze paresis by vestibular stimulation), or whether the lesion was restricted to neuronal loss in the caudal PPRF and/or abducens nucleus in the right pontine tegmentum. ${ }^{23}$ Later in her course, she developed a similar, but milder, conjugate gaze paresis to the left, and these findings were accounted for by the extensive gliosis and neuronal loss in the abducens nuclei found at autopsy.

This patient's EMG findings were of considerable interest. The initial repetitive stimulation studies (Figure 1) were suggestive but not diagnostic of myasthenia gravis. Moreover, the amplitude of the maximum "M" potentials were normal at first. This finding and the failure of the maximum " $M$ " potential to substantially increase in size in response to high frequency supramaximal stimulation of the motor nerve made the Lambert-Eaton syndrome unlikely. Marginal evidence of posttetanic facilitation and exhaustion was seen in the trapezius muscle, but there was no change following edrophonium. Throughout her illness, motor and sensory nerve conduction velocities were normal in the arms and legs. Single fiber needle EMG was attempted repeatedly but was unsuccessful because of poor patient co-operation. ALS was first suspected on the 24th hospital day when she developed tongue fasciculations. EMG confirmation was not forthcoming until 15 days prior to her death. Repeated needle electromyographic studies of clinically weak muscles failed to show any abnormalities in the shape or size of voluntarily recruited motor unit action potentials nor was there ever any evidence of linked potentials or impulse blocking. Repeat studies failed to show evidence of denervation activity at any time other than the examinations immediately prior to her death.

We have not seen a similar case of either a motor neuronopathy or rapidly progressive ALS in whom we have been unable to detect either changes in shape and size of motor unit potentials or evidence of denervation-reinnervation in clinically weak muscles prior to the terminal stage of the illness. These EMG findings contributed to the diagnostic uncertainty of this case. We do not have an adequate explanation for these observations. There were no recognizable alterations in serum biochemistry or in the patient's clinical status throughout the illness which might have contributed to these atypical electrophysiological findings. There was abundant evidence of anterior horn cell loss in the subsequent neuropathological examination to suggest that the characteristic EMG findings of ALS should have been present at a much earlier stage of the illness.

This case illustrates that the diagnosis of ALS or subacute motor neuronopathy may be difficult. These patients can present with features suggesting myasthenia gravis including clinical and electrophysiological findings and an apparent initial response to therapy. The diagnosis eventually becomes clear with the development of the progressive clinical course and inevitable resistance to therapeutic measures. In that a number of disturbances of ocular motility have been described in ALS, the occurrence of an eye movement disorder should not be taken as absolute evidence that an alternative diagnosis is required.

\section{ACKNOWLEDGEMENT}

The authors wish to acknowledge the secretarial assistance of Vivian Huard and Sandra Heydon. Dr. Noseworthy is supported by a Career Development Award from the Multiple Sclerosis Society of Canada.

\section{REFERENCES}

1. Mossman S, Vincent A, Newsom-Davis J. Myasthenia gravis without acetylcholine receptor antibody: A distinct clinical entity. Lancet 1986; i: 116-19.

2. Hirano A. Progress in the pathology of motor neuron diseases. Prog Neuropathol 1973; 2: 181-215.

3. Brownell B, Oppenheimer DR, Trevor Hughes J. The central nervous system in motor neuron disease. J Neurol Neurosurg Psychiat 1970; 33: 338-57.

4. Carpenter S. Proximal axonal enlargement in motor neuron disease. Neurology 1968; 18: 841-51.

5. Spencer PS, Schaumberg HH: Classification of neurotoxic disease: A morphological approach. In: Spencer PS, Schaumberg HH, eds. Experimental and Clinical Neurotoxicology. Williams and Wilkins, Baltimore, 1980, p 92.

6. Bonduelle M. Amyotrophic lateral stenosis. In: Vinken PJ, Bruyn GW, eds. Handbook of Clinical Neurology. Vol 22: System disorders and atrophies. New York: American Elsevier Publishing Co. 1975: 281-338.

7. Lambert EH, Mulder DW. Electromyographic studies in amyotrophic lateral sclerosis. Proc Staff Meet Mayo Clin 1957; 32: 441.46.

8. Mulder DW, Lambert EH, Eaton LM. Myasthenic syndrome in patients with amyotrophic lateral sclerosis. Neurology 1959; 9: 627-31.

9. Simpson JA. Disorders of neuromuscular transmission. Proc R Soc Med 1966; 59: 993-98.

10. Norris F.H. Nerve stimulation studies in amyotrophic lateral sclerosis. Fourth International Congress of Electromyography, Brussels, 1971; 106-7.

11. Denys EH, Norris FH Jr. Amyotrophic lateral sclerosis. Impairment of neuromuscular transmission. Arch Neurol 1979; 36: 202-5.

12. Mulder DW. Commentary. In: Mulder DW, ed. The diagnosis and treatment of amyotrophic lateral sclerosis. Boston: Houghton Mifflin Professional Publishers 1980;79.

13. Van Bogaert L. Contribution a la connaissance des troubles oculaires et vestibulaires dans la S.L.A. Rev Otoneuroophthalmol 1925; 3: 263-74.

14. Helfand M. Progressive bulbar palsy: Its pathology and relation to amyotrophic lateral sclerosis. J Nerv Ment Dis 1933; 78: 36280.

15. Lawyer $\mathrm{T} J \mathrm{~J}$, Netsky MG. Amyotrophic lateral sclerosis (a clinicoanatomic study of fifty-three cases). Arch Neurol Psychiatry 1953; 69: 171-92.

16. Jacobs L, Bozian D, Heffner R, Barron S. An eye movement disorder in amyotrophic lateral sclerosis. Neurology 1981; 31: 12827. 
17. Leveille A, Kiernan J, Goodwin JA, Antel J. Eye movements in amyotrophic lateral sclerosis. Arch Neurol 1982; 39:684-86

18. Harvey DG, Torack RM, Rosenbaum HE. Amyotrophic lateral sclerosis with ophthalmoplegia. A clinicopathological study. Arch Neurol 1979; 36: 615-17.

19. Walsh FB, Hoyt WF: Heredofamilial and degenerative diseases. ln: Walsh FB, Hoyt AB, eds. Clinical Neuro-Ophthalmology. Third Edition. Baltimore: Williams and Wilkins Co., 1969; 1: 936-38.

20. McGlone J, Hudson AJ. An eye movement disorder in ALS.
Neurology 1983; 33: 254.

21. Kushner MJ, Parrish M, Burke A, et al. Nystagmus in molor neuron disease: Clinicopathological study of two cases. Ann Neurol 1984; 16: 71-77.

22. Esteban A, De Andres C, Gimenez-Roldan S. Abnormalities of Bell's phenomenon in amyotrophic lateral sclerosis. J Neurol Neurosurg Psychiatry 1978; 41: 690-98.

23. Wall M, Wray SH. The one-and-a-half syndrome. A unilateral disorder of the pontine tegmentum: A study of 20 cases and review of the literature. Neurology 1983; 33: 971-80. 